\title{
Interhospital transport of ARDS patients on extracorporeal membrane oxygenation
}

\author{
Jan Florian Heuer ${ }^{1,2} \cdot$ Moritz Mirschel $^{2} \cdot$ Annalen Bleckmann $^{3} \cdot$ Michael Quintel $^{2} \cdot$ Onnen Moerer ${ }^{2}$
}

Received: 16 January 2018 / Accepted: 2 August 2018 / Published online: 18 August 2018

(C) The Japanese Society for Artificial Organs 2018

\begin{abstract}
Veno-venous extracorporeal membrane oxygenation (ECMO) can be a lifesaving therapy for patients with severe acute respiratory distress syndrome (ARDS). ECMO is a technically complex and challenging procedure and should therefore only be performed in specialized centers. Transporting ARDS patients to ECMO centers for treatment can be dangerous because of the risk of hypoxemia during transport. This raises the question if ECMO should not be already initiated in the transferring hospital before transport. Over a 5-year period, we studied ARDS patients who had been transported to our department by our mobile ECMO team for further treatment after ECMO had already been initiated at the referring hospital. Data for analysis were obtained from our patient data management system (PDMS), the referral documents, and from the referring hospitals. Seventy-five patients meeting the selection criteria were studied. All had been successfully cannulated in the transferring hospitals. They were transported to our ECMO center by helicopter $(n=34)$ or mobile intensive care units $(n=41)$. No patient died during transport. Forty four of the patients were transported at night. Twenty-six patients (35\%) died in our intensive care unit due to a therapy refractory course, comorbidities or limitation of therapy. Patients on ECMO therapy can be safely transferred to a specialist center. Setting up ECMO in an unfamiliar location and the subsequent patient transport can be very challenging and should only be performed by a highly trained, experienced team.
\end{abstract}

Keywords ECMO $\cdot$ Transferring hospitals $\cdot$ Helicopter $\cdot$ Mobile intensive care units $\cdot$ Outcome

\section{Introduction}

Severe acute respiratory distress syndrome (ARDS) is still a highly lethal condition, although lung protective ventilation with small tidal volumes (6-8 $\mathrm{ml} / \mathrm{kg}$ IBW) [1], prone

Electronic supplementary material The online version of this article (https://doi.org/10.1007/s10047-018-1065-y) contains supplementary material, which is available to authorized users.

Jan Florian Heuer

j.heuer@augusta-bochum.de

Moritz Mirschel

moritz.mirschel@vivantes.de

Annalen Bleckmann

a.bleckmann@med.uni-goettingen.de

Michael Quintel

mquintel@med.uni-goettingen.de

Onnen Moerer

omoerer@gwdg.de positioning [2], low driving pressures [3], and neuromuscular blockade [4] can reduce its mortality rate.

If conventional respiratory therapy is no longer able to preserve the life of ARDS patients, they should be transferred to specialized centers. But this can be hazardous because of the risk of severe hypoxemia during transport. Veno-venous extracorporeal membrane oxygenation (VVECMO) is an advanced therapeutic option in patients with severe ARDS in case of a reversible underlying pulmonary

1 Department of Anesthesiology, Intensive Care Medicine, Emergency Medicine and Pain Management, AugustaKliniken Bochum-Mitte, Bochum, Germany

2 Department of Anesthesiology, Intensive Care Medicine, Emergency Medicine and Pain Management, University Medical Center Göttingen, Göttingen, Germany

3 Department of Medical Statistics, University Medical Center Göttingen, Göttingen, Germany 
disorder. With the availability of better pumps, oxygenators and other equipment, it has become an almost standard procedure for specialized centers. The unresolved question, although there is already some data published [5-7], is whether the risk of moving the patient could be reduced if ECMO were started already in the referring hospital and continued during transport. We addressed this question by analyzing the results of our mobile ECMO team that initiated ECMO in the referring hospital and accompanied the patients to our institution.

\section{Materials and methods}

\section{ECMO program: equipment and organization}

Our institution initiated the ECMO transport program in 2006. From 2006 until 2010 a Bio Medicus ${ }^{\circledR} 550$ centrifugal pump console (Medtronic) was used for ECMO transports, which was then replaced by a ROTAFLOW ${ }^{\circledR}$ (Maquet) centrifugal pump. Since 2013, the CARDIOHELP® system (Maquet, Cardiopulmonary, Rastatt, Germany) has been used in nearly all transports. A backup ECMO pump was not carried during transport, but the ECMO pumps could be operated with a crank handle in case they failed.

In all instances, a Quadrox-D ${ }^{\circledR}$ oxygenator (Maquet) and the Maquet PLS, respectively, the HLS biocoated tubing set (PLS system, Maquet) was used.

Short-distance transports under ECMO support were by mobile intensive care ambulances. Long-distance transport was by helicopters. The ECMO team consisted of two intensive care physicians (intensivists) with experience in dealing with ARDS patients under ECMO therapy. All physicians were anesthesia and critical care specialists with more than 7 years of clinical training and at least 2 years of experience in the treatment of ARDS and ECMO patients. Every ECMO team leader had personally performed at least 15 ECMO cannulations.

Our institution provided the material and equipment required for ECMO therapy.

The referring hospitals contacted our intensive care unit and supplied the data for the initial ECMO questionnaire. Our ICU then contacted a member of the ECMO team, who decided if an ECMO transport was necessary. The decision to send out the mobile ECMO team was based on the patient's actual pulmonary status such as ventilator settings, $\mathrm{paO}_{2}$ and the corresponding oxygenation ratio ( $P / F$-ratio), $\mathrm{paCO}_{2}$ values and the time dynamic of the pulmonary deterioration, X-rays or CT scans. Moreover recent and past medical history, organ function, lactate levels, infusion rates of vasoactive drugs, and the overall hemodynamic status were considered for the decision process.

\section{Patients}

With approval of our institutional review board, all patients with ARDS who had been equipped with an ECMO system from our ECMO team in a peripheral hospital and transferred to our center for further treatment in the period from January 2009 to October 2013 were recruited for this study.

\section{Patient care}

After arrival in the referring hospital, the ECMO team examined the patient and reevaluated the necessity of an ECMO system for transport. If the decision was for ECMO, the cannulas were inserted percutaneously over wire guides. One was placed in the right femoral vein for blood outflow [21-25 Fr lumen catheter (DLC)], and one in the right internal jugular vein (17-23/32 Fr Avalon Elite Bi-Caval®) for return flow. The tip of the outflow cannula was positioned approximately at the level of the hepatic vein, and that of the return flow cannula was in the superior vena cava. The cannulas were secured with two sutures and an adhesive bandage that covered almost the entire cannula to prevent cannula dislocation. Before transport all patients also received either two large bore i.v. catheters or a dialysis catheter for the event that the suction in the lower ECMO cannula might collapse the inferior vena cava due to insufficient preload. This would result in an immediate reduction of ECMO flow that would endanger the patient.

The ECMO system itself had already been primed in our institution before departure. After the cannulas were inserted, the ECMO system was connected and started. The initial gas flow was set at 11 per minute, and pump flow was set according to the required oxygenation. The correct location of the cannulas was documented by chest X-ray. Blood gases were analyzed after starting ECMO and again after the patient had been connected to the transport ventilator. The ventilator settings were decreased towards lung protective values to maintain a plateau pressure significantly less than $28 \mathrm{cmH}_{2} \mathrm{O}$, a tidal volume less than $8 \mathrm{ml} / \mathrm{kg}$ of predicted body weight, and the lowest possible inspired oxygen fraction. During transport, heart rate, oxygen saturation, endtidal $\mathrm{CO}_{2}$, peak pressures and arterial blood pressure were monitored. A whole-body CT scan was performed immediately after arrival at our medical center.

\section{Data acquisition}

Patient data were extracted retrospectively from our patient data management system, the hospital's electronic medical 
record system, the ECMO transport form, and from the documents from the referring hospital.

\section{Statistical analysis}

The data were analyzed with the statistical software $\mathrm{R}$ (http://www.r-project.org). Data are presented as median and interquartile range (IQR) and as mean and standard deviation.

Changes from baseline in each individual series were assessed with the Wilcoxon rank test for paired samples.

\section{Results}

75 patients fulfilled our inclusion criteria and were cannulated by our ECMO team; none of these patients were left in the referring hospital. Twelve transports were in 2009, eight in 2010, 28 in 2011, twelve in 2012, and 15 in 2013. ESM Table 1 gives their demographic data. A list of the underlying pulmonary diseases is given in Table ESM 2.

Eight patients did not require immediate veno-venous ECMO treatment in the transferring hospital. Their gas exchange was adequate after optimizing ventilator settings and patient positioning, and they were transported without ECMO. However, one of these patients did require cannulation after admission. No patient was left in the referring hospital.

All patients survived the transport. Thirty-four patients were transported by helicopter and 41 by mobile intensive care ground units (Fig. 1). Forty-four transports occurred at night. The mean distance from the referring hospital to our medical center was $116 \pm 91.6$ kilometers. No technical problems arose with the ECMO equipment during any of the missions.

49 patients $(65 \%)$ were transferred to a normal ward or returned to the referring hospitals after ECMO and ARDS treatment. Twenty-six patients (35\%) died despite ECMO therapy, five of them (7\%) already within the first $24 \mathrm{~h}$. Two of the latter already had a massive malignant cerebral edema on arrival diagnosed with a cerebral CT scan, and the other three remained in multiorgan failure with persisting need for extremely high catecholamine infusion rates $(\geq 100 \mu \mathrm{g}$ norepinephrine/min) (Table ESM 3).

The survival rates were $67,62.5,71,75$ and $46.7 \%$ in the years 2009-2013, respectively. The ECMOnet-Scores calculated at the time of hospital admission did not differ significantly between subsequent survivors and non-survivors.

The patients had been in the peripheral hospital for a median of 5 [2-8] days and had been on the ventilator for a median of 1 [1-5] day before ECMO was started. The median duration of ECMO treatment was 8 [6-12] days.

Before ECMO therapy the majority of the patients was ventilated in pressure-controlled mode. Before beginning ECMO, the mean peak airway pressure (Pinsp) was $33.1 \pm 5.2 \mathrm{cmH}_{2} 0$, PEEP was $15.4 \pm 3.4 \mathrm{cmH}_{2} 0, \mathrm{FiO}_{2}$ was 1.0 , the respiratory minute volume was $10.1 \pm 3.2, \mathrm{paO}_{2}$ was $73.1 \pm 23.1 \mathrm{mmHg}, \mathrm{paCO}_{2}$ was $63.6 \pm 22.4 \mathrm{mmHg}$ and the $\mathrm{pH}$ was $7.25 \pm 1.3 \mathrm{mmol} / \mathrm{l}$ (Table 2). The mean SAPS II score at admission to our facility was $62 \pm 12$.

The comparison between survivors and non-survivors at the time of ECMO placement showed a significant
Fig. 1 Flowchart showing total number of patients, who were treated with an ECMO system before transport. The kind of transport and the final outcome is shown for the sub cohorts

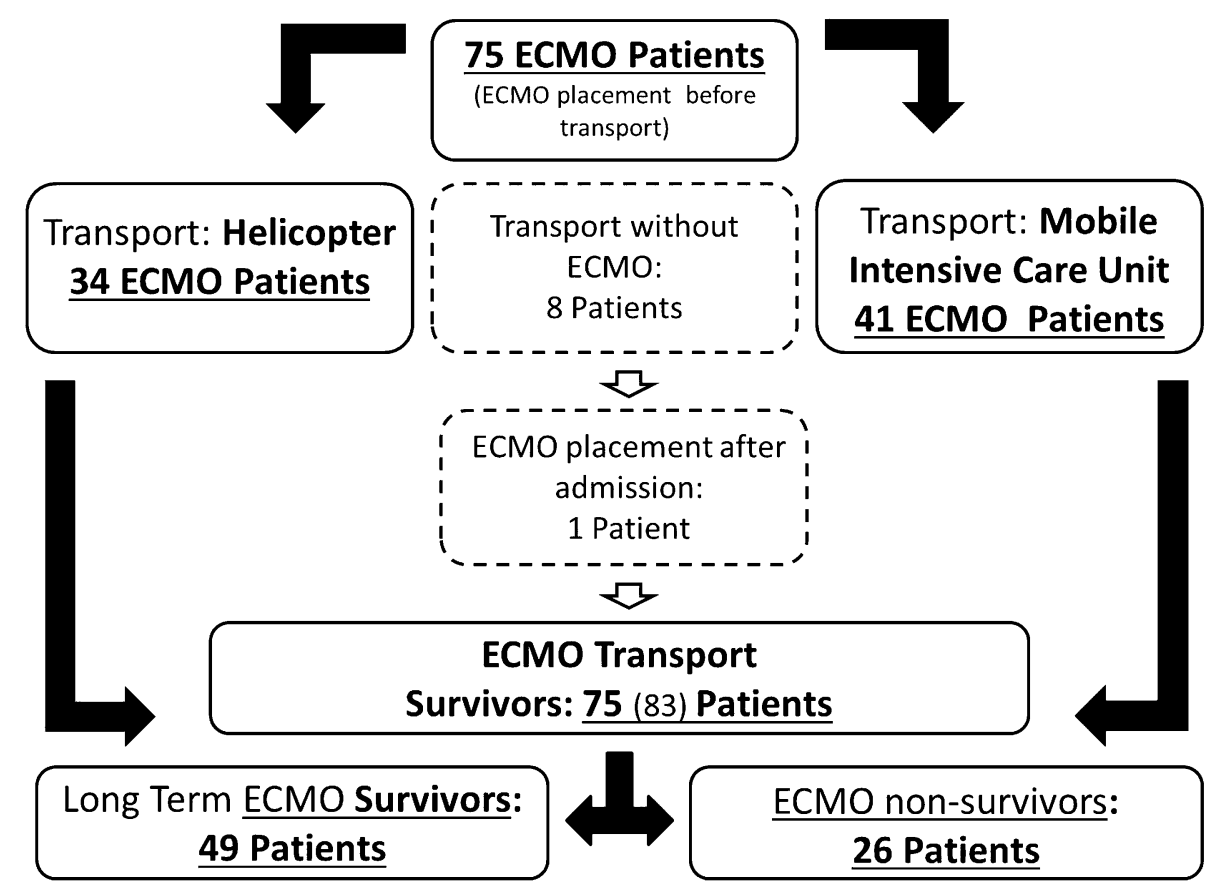


difference in $\mathrm{pH}(7.29 \pm 1.2$ vs $7.19 \pm 1.2), \mathrm{paCO}_{2}(59 \pm 17.4$ vs $72.7 \pm 28.4)$ and $\mathrm{SaO}_{2}(90.5 \pm 9.7$ vs $86.8 \pm 8.3)$, but not in peak airway pressure, PEEP, respiratory rate, minute volume or $\mathrm{FiO}_{2}$ (Table 1, Fig. 2). At admission to the ECMO center, there were no differences in the gas exchange anymore.

Twenty-four hours after beginning ECMO therapy, the mean Pinsp was $24 \pm 3.9 \mathrm{cmH}_{2} \mathrm{O}$, PEEP was $13.6 \pm 3.4$ $\mathrm{cmH}_{2} 0, \mathrm{FiO}_{2}$ was $0.5 \pm 0.2$, the minute volume was $6.3 \pm 3.3 \mathrm{l} / \mathrm{min}$, $\mathrm{paO}_{2}$ was $89.9 \pm 66 \mathrm{mmHg}$, the $\mathrm{paCO}_{2}$ was $39.6 \pm 6.7 \mathrm{mmHg}$ and the $\mathrm{pH}$ was $7.43 \pm 0.08 \mathrm{mmol} / \mathrm{l}$.

The median ECMO flow after $24 \mathrm{~h}$ was $4.3[3.8-5.1] 1 / \mathrm{min}$ and the gas flow was $5.0[3.8-6] 1 / \mathrm{min}$.

High frequency oscillatory ventilation (HFOV) was used in $43 \%$ of the patients during the ARDS treatment.

\section{Discussion}

This study shows patients on extracorporeal membrane oxygenation (ECMO) can be safely transported between hospitals. None of the studied patients died during transport, even though a high percentage of the transports occurred under difficult conditions. Since more than $40 \%$ of the ECMO transports were during nighttime, and more than $45 \%$ of the transports were by helicopter, where space for movement is very limited. In addition, our ECMO team consisted of two experienced intensivists and one (flight) paramedic; there was no vascular surgeon, perfusionist or intensive care nurse involved, as opposed to most other mobile ECMO programs [6, 8-11].

It should be noted that the ECMO patients who died after admission to the ECMO center in comparison to the patients who survived ECMO, had at the moment of ECMO placement significant differences in $\mathrm{pH}, \mathrm{paCO}_{2}$ and $\mathrm{SaO}_{2}$. At arrival at the ECMO center, the differences were not existent any more (Table 1 ). The fact that there were no differences in gas exchange after ECMO transport anymore underlines the safety of ECMO transports, if the transport is done by a specialized and well-trained team.

Although ECMO therapy has become almost a routine procedure for severe ARDS with therapy refractory hypoxemia, one must remember that ECMO is still a very invasive procedure with potentially life-threatening complications, especially when the patient is being moved [12].

Lung failure still has a high mortality rate [13], and the treatment of ARDS is complex and often challenging. Mortality can be reduced, i.a. by lung protective ventilation [1], implementing prone positioning [2] and keeping the driving pressure to less than $15 \mathrm{cmH}_{2} \mathrm{O}$ [3], but not all hospitals consistently implement these therapeutic measures. If hypercapnia occurs, the peak airway pressure is often kept high and PEEP decreased to increase tidal volume. But this

Table 1 Blood gas and ventilation parameters at initiation of ECMO therapy and at arrival in the university medical center

\begin{tabular}{|c|c|c|c|c|}
\hline Blood gas & Survivors before ECMO & $\begin{array}{l}\text { Non-survivors- } \\
\text { Before ECMO }\end{array}$ & $\begin{array}{l}\text { Survivors at admission } \\
\text { after ECMO placement }\end{array}$ & $\begin{array}{l}\text { Non-survivors at admis- } \\
\text { sion after ECMO place- } \\
\text { ment }\end{array}$ \\
\hline $\mathrm{pH}$ & $7.29 \pm 0.12 *$ & $7.19 \pm 0.12$ & $7.44 \pm 0.12$ & $7.40 \pm 0.14$ \\
\hline $\mathrm{paO}_{2}(\mathrm{mmHg})$ & $76.1 \pm 26.6$ & $67.0 \pm 12.5$ & $96.1 \pm 65.1$ & $91.5 \pm 47.4$ \\
\hline $\mathrm{paCO}_{2}(\mathrm{mmHg})$ & $59.0 \pm 17,4^{*}$ & $72.7 \pm 28.4$ & $35.62 \pm 8.19$ & $36.1 \pm 7.5$ \\
\hline $\mathrm{SaO}_{2}$ & $90.5 \pm 9.7^{*}$ & $86.8 \pm 8.3$ & $96.1 \pm 3.5$ & $97.2 \pm 2.2$ \\
\hline \multicolumn{5}{|l|}{ Ventilation } \\
\hline Peak airway pressure & $33.2 \pm 5.6$ & $32.9 \pm 4.0$ & $25.1 \pm 5.7$ & $26.1 \pm 3.0$ \\
\hline $\operatorname{PEEP}\left(\mathrm{cm} \mathrm{H}_{2} \mathrm{O}\right)$ & $15.4 \pm 3.5$ & $16.0 \pm 4.1$ & $14 \pm 4.3$ & $13.5 \pm 3.1$ \\
\hline Respiratory rate & $22.6 \pm 5.2$ & $22.6 \pm 4.6$ & $19.8 \pm 5.6$ & $21.9 \pm 6.8$ \\
\hline Minute volume (1) & $10.6 \pm 3.4$ & $9.3 \pm 2.6$ & $4.3 \pm 2.6$ & $3.9 \pm 2.3$ \\
\hline $\mathrm{FiO}_{2}$ & $1.0 \pm 0.1$ & $1.0 \pm 0.1$ & $0.7 \pm 0.2$ & $0.8 \pm 0.2$ \\
\hline Days in hospital before ECMO (d) & $\begin{array}{l}5.7 \pm 5.7 \\
4[2-7]\end{array}$ & $\begin{array}{l}10 \pm 12.9^{\#} \\
6[2.8-10.3]\end{array}$ & - & - \\
\hline Days on ventilator before ECMO (d) & $\begin{array}{l}3.4 \pm 4.1 \\
1[1-5]\end{array}$ & $\begin{array}{l}4.0 \pm 5.8 \\
2[1-5]\end{array}$ & - & - \\
\hline Days of ECMO treatment (d) & $\begin{array}{l}10.4 \pm 7.2 \\
9(6-11.5)\end{array}$ & $\begin{array}{l}9.5 \pm 9.1 \\
7(3.3-16)\end{array}$ & - & - \\
\hline
\end{tabular}

Values are mean \pm standard deviation and total number or median and 25 and $75 \%$ quartile

Survivors long-term survivors, non-survivors patient that died after Admission to the ICU in the university medical center, $\mathrm{cmH} 2 \mathrm{O}$ centimeter water, $l$ liter, $E C M O$ extracorporeal membrane oxygenation, $\mathrm{FiO} 2$ oxygenation concentration, $\mathrm{paO} 2$ arterial oxygenation tension, $\mathrm{paCO} 2$ arterial carbon dioxide tension, $H b$ hemoglobin, $P E E P$ positive end expiratory pressure

*Signifies a significant difference between the groups $(p<0.05)$ 


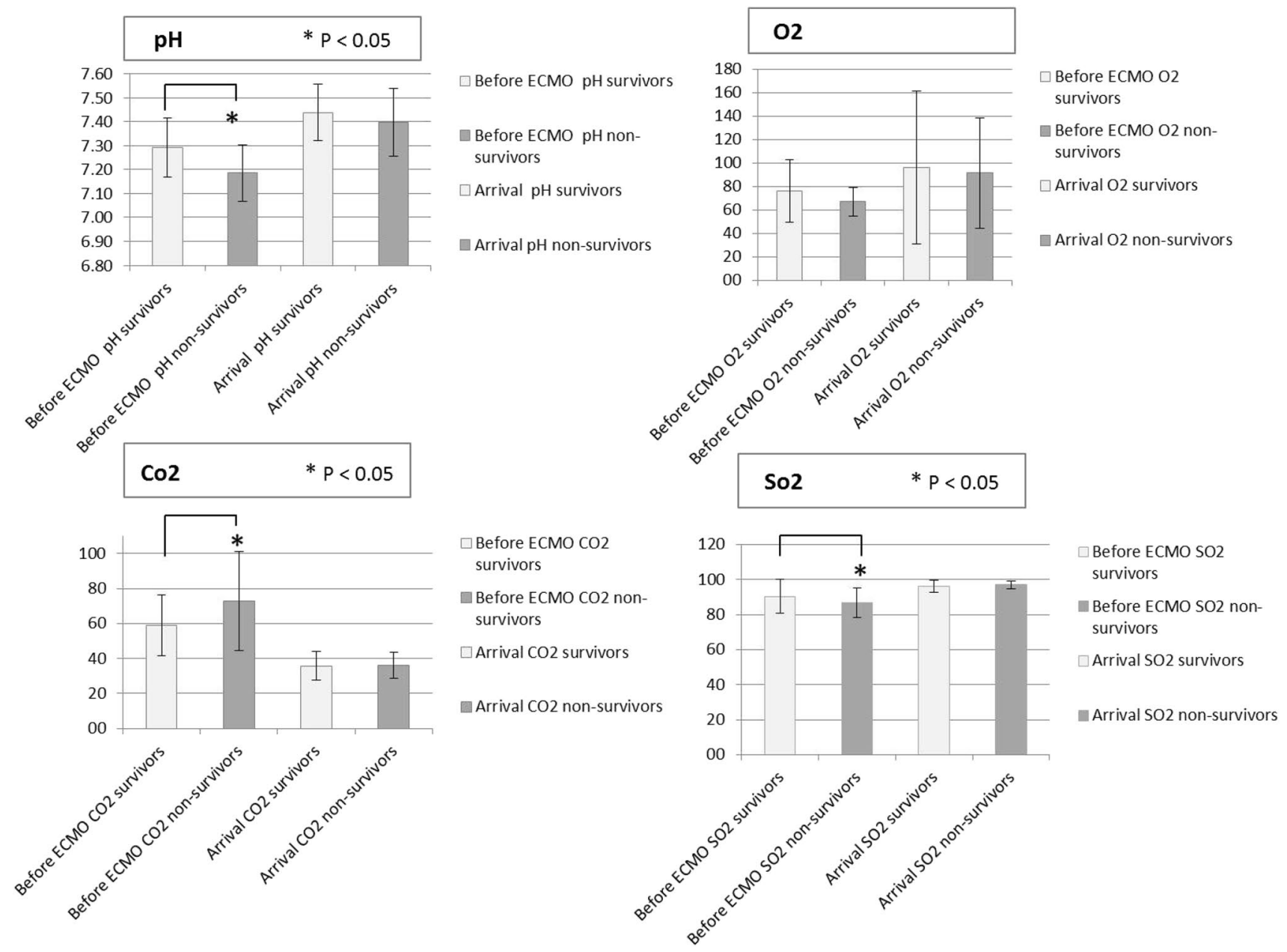

Fig. 2 Data are presented as mean and standard deviation; Before ECMO before ECMO placement; Arrival: arrival at the university medical center with ECMO support; $\mathrm{O}_{2}$ Oxygen: $\mathrm{CO}_{2}$ carbon dioxide, $\mathrm{SO}_{2}$ oxygen saturation; significant: $p<0.05$

increases the driving pressure and has an impact on ventilator induced lung injury, which then increases morbidity, and mortality $[3,14]$.

This is where ECMO can be of use. Peek et al. demonstrated in the Ceasar trial that mortality rates are higher in hospitals that do not have an ECMO program than in specialized ECMO centers. The conclusion was that patients with severe ARDS should be transferred to tertiary centers [7] that are experienced in ARDS and ECMO treatment. But the transport of critically ill patients between hospitals is dangerous, because of the adverse events that can occur [15].

Ligtenberg et al. reported a $34 \%$ incidence of adverse events occurring during patient transport, of which a large number involved respiratory problems in patients with respiratory failure being transported without an ECMO system [16]. It is therefore more than appropriate to enable a safe and gentle inter-hospital transfer of critically ill, particularly hypoxemic patients. ECMO can very rapidly normalize oxygenation and $\mathrm{CO}_{2}$ elimination, how our data show. Of note is that two patients in the CESAR study, who were transported without an ECMO system died during transport, while no deaths occurred in patients with ECMO support [7].

Broman et al. [7] published a study with the largest number of patients transferred with on-going ECMO treatment [10]. There were 282 ECMO patients who had been transported by fixed-wing aircraft, helicopter or ground unit after ECMO cannulation in the referring hospitals. The authors also transported small children and neonates and consider mobile ECMO transports to be both feasible and safe. They documented complications in $27.3 \%$ of the transports. The complications were categorized in the following five groups: patient, staff, equipment, vehicle and environment.

Although a large proportion of our transports were done under difficult conditions, i.e., at night and with restricted room for movement, the only documented serious event was a sudden reduction in the ECMO flow due to hypovolemia. Fluid reduction can be an effective therapeutic measure in pulmonary failure [17], but intravascular hypovolemia can 
reduce flow during ECMO therapy, which immediately results in hypoxemia. To be prepared for hypovolemia, an additional large-bore venous access should be established for immediate fluid resuscitation before transport, and infusions of vasoactive drugs must be immediately available.

The immediate application of a high ECMO flow rapidly increases $\mathrm{paO}_{2}$, but inhibits hypoxic pulmonary vasoconstriction (HPV) [18] and thus increases shunt perfusion. Inhibition of HPV by ECMO therapy can pose a severe risk for the patient, because conventional ventilation, that might have been just sufficient prior to ECMO, will no longer be able to provide adequate oxygenation should the ECMO flow be interrupted.

Another problem observed during transport was a too rapid reduction of $\mathrm{paCO}_{2}$, which can cause cerebral ischemia [19]. Since hypercapnia is generally not life-threatening, the sweep gas flow should not be higher than 11 per minute when starting ECMO treatment.

Biscotti et al. reported no deaths in 79 patients who had been transported with a mobile veno-venous ECMO system. They did describe two severe complications, an accidental decannulation, and an incidence of pump failure. As mentioned above, pump failure can cause immediate, fatal hypoxemia because HPV is suppressed. A backup ECMO system should therefore always be carried along. Because of the weight constraints in the helicopter the ECMO team did not carry a backup ECMO pump, but did have a crank handle in case of pump failure. One might criticize this approach, but we encountered no technical problems during transport. In their report, Roch et al. described 85 patients who had been treated with an ECMO system in the referring hospital with no occurrence of death or serious complications during transport. Lucchini and colleagues also reported no deaths during the transport of 28 patients on veno-venous ECMO [6].

Five of the ECMO patients transferred to our hospital died within $24 \mathrm{~h}$ after arrival. In two patients, the cerebral CT scan on arrival showed massive edema, and palliative care was started. Without the transport made possible by ECMO there would have been no CT scan, since the referring hospital did not have the facilities. Whether transport with ECMO support is indicated in such a case is debatable, but without it, the ultimately futile therapy would have continued, and the family's suffering would have been prolonged. The other three patients were in an extremely unstable circulatory state before cannulation that could not be stabilized due to VV-ECMO treatment.

No patient was left in the referring hospital, not even ones with circulatory failure, because the necessary treatment was only possible in a specialized ARDS center. The mean SAPS II scores of $62 \pm 12$ and the very invasive ventilator support (Table 2) in almost all patients illustrate the severity of the pulmonary failure of the patients.
Table 2 Blood gas and ventilation parameters before and $24 \mathrm{~h}$ after initiation of ECMO therapy

\begin{tabular}{lll}
\hline & Before ECMO & 24 h with ECMO \\
\hline $\mathrm{pH}$ & $7.25 \pm 1.3$ & $7.43 \pm 0.01^{*}$ \\
$\mathrm{FiO}_{2}$ & $1.0 \pm 0.1$ & $0.5 \pm 0.2^{*}$ \\
$\mathrm{paO}_{2}(\mathrm{mmHg})$ & $72.1 \pm 23.1$ & $89.9 \pm 66^{*}$ \\
$\quad$ Oxygenation ratio (Horo- & $74.0 \pm 28.5$ & $168.9 \pm 81.8$ \\
$\quad$ vitz Index) & & \\
$\mathrm{paCO}_{2}(\mathrm{mmHg})$ & $63.6 \pm 22.4$ & $38.6 \pm 8.3^{*}$ \\
$\mathrm{Lactate}(\mathrm{mg} / \mathrm{dl})$ & $3.8 \pm 4.8$ & $2.3 \pm 1.7$ \\
$\mathrm{Hb}(\mathrm{mg} / \mathrm{dl})$ & $11 \pm 2.2$ & $9.6 \pm 1.5^{*}$ \\
Peak airway pressure & $33.1 \pm 5.2$ & $24.3 \pm 3.9^{*}$ \\
$\mathrm{PEEP}\left(\mathrm{cmH} \mathrm{H}_{2} \mathrm{O}\right)$ & $15.4 \pm 3.4$ & $13.6 \pm 3.4^{*}$ \\
Respiratory rate & $22.6 \pm 5$ & $22.9 \pm 7.5$ \\
Minute volume (l) & $10.1 \pm 3.2$ & $6.3 \pm 3.3^{*}$ \\
\hline
\end{tabular}

Values are mean \pm standard deviation and total number

$m g$ milligram, $d l$ deciliter, $\mathrm{cm}$ centimeter, $\mathrm{cmH} 2 \mathrm{O}$ centimeter water, $l$ liter, ECMO extracorporeal membrane oxygenation, $\mathrm{FiO} 2$ oxygenation concentration, $\mathrm{paO} 2$ arterial oxygenation tension, $\mathrm{paCO} 2$ arterial carbon dioxide tension, $H b$ hemoglobin, PEEP positive end expiratory pressure, $h$ hours

*Signifies a significant difference between the groups $(p<0.05)$

Nevertheless, the question arises whether transporting a patient with circulatory failure is justified. This leads to the question of whether a veno-venous-arterial (VVA) ECMO system might not be a better choice since it supports both the failing lungs and heart and while this is a valid consideration, its implementation in a transport or airlift situation is not possible. VVA-ECMO requires a second flow sensor, a flow reduction device and a third (arterial) cannula, and there is neither an ECMO pump with a second flow measurement nor a professional flow reduction device on the market that could be used under these conditions. VA-ECMO is also not an option, because the extremely high ECMO flow required in complete pulmonary failure would increase left heart afterload and would as a result cause left ventricular dilation and pulmonary edema.

For the future, the ECMOnet score might be a promising tool to help select the right patients for ECMO retrievals [20]. This score comprises five factors: serum bilirubin and serum creatinine concentrations, mean systemic arterial pressure, hematocrit, and duration of hospital stay before request for ECMO. The simplicity of that score will maybe offer ECMO centers in a short period of time to choose the right patient. Although there was no significant difference in the ECMOnet score between survivors and non-survivors in our study, higher pre-ECMO scores generally indicate a poorer outcome. But since the score was not determined in our patients before ECMO therapy but only under ECMO treatment when admitted to our hospital, the lack 
of a significant difference is not surprising. In addition, the ECMOnet Score had not been established when our data collection began.

As mentioned above, the most important goal for the future will be to select the appropriate patients; if ECMOsupported transport is used in an inflationary manner, the procedure can be discredited. However, it would have been a mistake to reject patients with initial hemodynamic instability because this is frequently reversible once ECMO has alleviated the severe hypoxemia that was responsible for the circulatory depression, particularly the right heart failure. But it is our experience that even with the help of a specialized ECMO questionnaire and personal telephone contact, the decision whether ECMO should be initiated in the referring hospital is very difficult. An additional complicating factor is the often incomplete and unsatisfactory data, including medical history that is available from the referring hospital. When in doubt, a mobile ECMO team should organize an ECMO transport and carefully examine the patient and the relevant documents in the referring hospital before making a final decision. As mentioned before no patient died during transport and furthermore patients even "improved" during transport, so an ECMO transport is more than justified, if the indication is right.

Our survival rate of $65 \%$ is similar to that in most other studies; Biscotti et al. 63\% [8], Lucchini et al. 76\% [6], Raspe et al. 64\% [11], Forrest et al. 86\% [5] and Roch et al. $44 \%$ [9].

As already mentioned above, our ECMO team only comprised of two experienced intensivists. We chose this restriction to guarantee the availability of an ECMO team around the clock. And reports from the CESAR trial, in which three patients that were randomized to the ECMO group died in the $48 \mathrm{~h}$ before transfer [7], illustrate the importance of an expeditiou transfer. Keeping a larger ECMO team available on a 24-h basis is difficult, and might not be feasible due to personnel and financial constraints. However, our study shows that a smaller team consisting of two intensivists that is experienced in ECMO treatment is able to provide the service with the same degree of safety as obtained with larger teams (Table 1). Another very important advantage of an ECMO team that only consists out of two members is the fact that a regular emergency rescue helicopter with a limited number of seats can be used for the ECMO transport.

Because of the promising results of this as well as previous studies we believe that ECMO retrievals can be performed without serious complications. Due to the high mortality rates of ARDS patients, patients with severe respiratory failure should be transferred to specialized ARDS centers. Since mobile ECMO transports are possible at any time of day, patients should not have to remain in a hospital that lacks experience in dealing with ARDS patients for longer than necessary. For best results, adequate ARDS treatment should be started as soon as possible which means that specialized ECMO centers must be able to provide around the clock ECMO transport.

\section{Limitations}

A limitation of the study is the retrospective design; more precise data collection would have been possible in a prospective study. But when the mobile ECMO program was started one did not anticipate that ECMO retrievals would be necessary on an almost routine basis. In the future, all the data necessary for calculating mobile ECMO scores must be collected to make the selection of appropriate patients easier.

\section{Conclusions}

ECMO transports can be safely conducted by a team of two intensivists who are experienced in the management of ARDS and ECMO. The transports can by helicopter be performed with limited space for movement and during the night without effecting patient safety. One should no longer delay the transfer of ARDS patients to ECMO centers, because ECMO transports can be performed safely at any time.

Author contributions JFH, MM, MQ, OM planned and designed the study. MM, JFH, and OM collected and analysed the data. All authors (JFH, MM, MQ, AB and OM) participated in the analysis and interpretation of the results. $\mathrm{AB}$ performed the statistical analysis. The final manuscript was drafted by JFH and OM and was discussed and approved by all participating authors.

\section{Compliance with ethical standards}

Conflict of interest The authors declare that they have no conflict of interests.

\section{References}

1. Ventilation with lower. tidal volumes as compared with traditional tidal volumes for acute lung injury and the acute respiratory distress syndrome. the acute respiratory distress syndrome network. N Engl J Med. 2000;342:1301-8.

2. Guerin C, Reignier J, Richard JC. Prone positioning in the acute respiratory distress syndrome. N Engl J Med. 2013;369:980-1.

3. Amato MB, Meade MO, Slutsky AS, Brochard L, Costa EL, Schoenfeld DA, et al. Driving pressure and survival in the acute respiratory distress syndrome. N Engl J Med. 2015;372:747-55.

4. Papazian L, Forel JM, Gacouin A, Penot-Ragon C, Perrin G, Loundou A, et al. Neuromuscular blockers in early acute respiratory distress syndrome. N Engl J Med. 2010;363:1107-16.

5. Forrest P, Ratchford J, Burns B, Herkes R, Jackson A, Plunkett B, et al. Retrieval of critically ill adults using extracorporeal membrane oxygenation: an Australian experience. Intensive Care Med. 2011;37:824-30. 
6. Lucchini A, De Felippis C, Elli S, Gariboldi R, Vimercati S, Tundo P, et al. Mobile ECMO team for inter-hospital transportation of patients with ARDS: a retrospective case series. Heart Lung Vessels. 2014;6:262-73.

7. Peek GJ, Mugford M, Tiruvoipati R, Wilson A, Allen E, Thalanany MM, et al. Efficacy and economic assessment of conventional ventilatory support versus extracorporeal membrane oxygenation for severe adult respiratory failure (CESAR): a multicentre randomised controlled trial. Lancet. 2009;374:1351-63.

8. Biscotti M, Agerstrand C, Abrams D, Ginsburg M, Sonett J, Mongero $\mathrm{L}$, et al. One hundred transports on extracorporeal support to an extracorporeal membrane oxygenation center. Ann Thorac Surg. 2015;100:34-9. (discussion 9-40).

9. Roch A, Hraiech S, Masson E, Grisoli D, Forel JM, Boucekine $\mathrm{M}$, et al. Outcome of acute respiratory distress syndrome patients treated with extracorporeal membrane oxygenation and brought to a referral center. Intensive Care Med. 2014;40:74-83.

10. Broman LM, Holzgraefe B, Palmer K, Frenckner B. The Stockholm experience: interhospital transports on extracorporeal membrane oxygenation. Crit Care. 2015;19:278.

11. Raspe C, Ruckert F, Metz D, Hofmann B, Neitzel T, Stiller M, et al. Inter-hospital transfer of ECMO-assisted patients with a portable miniaturized ECMO device: 4 years of experience. Perfusion. 2015;30:52-9.

12. Gattinoni L, Carlesso E, Langer T. Clinical review: Extracorporeal membrane oxygenation. Crit Care. 2011;15:243.
13. Zambon M, Vincent JL. Mortality rates for patients with acute lung injury/ARDS have decreased over time. Chest. 2008;133:1120-7.

14. Costa EL, Slutsky AS, Amato MB. Driving pressure as a key ventilation variable. N Engl J Med. 2015;372:2072.

15. Parmentier-Decrucq E, Poissy J, Favory R, Nseir S, Onimus T, Guerry MJ, et al. Adverse events during intrahospital transport of critically ill patients: incidence and risk factors. Ann Intensive Care. 2013;3:10.

16. Ligtenberg JJ, Arnold LG, Stienstra Y, van der Werf TS, Meertens $\mathrm{JH}$, Tulleken JE, et al. Quality of interhospital transport of critically ill patients: a prospective audit. Crit Care. 2005;9:R446-51.

17. Wiedemann HP, Wheeler AP, Bernard GR, Thompson BT, Hayden $\mathrm{D}$, deBoisblanc B, et al. Comparison of two fluid-management strategies in acute lung injury. N Engl J Med. 2006;354:2564-75.

18. Sommer N, Dietrich A, Schermuly RT, Ghofrani HA, Gudermann $\mathrm{T}$, Schulz R, et al. Regulation of hypoxic pulmonary vasoconstriction: basic mechanisms. Eur Respir J. 2008;32:1639-51.

19. Curley G, Kavanagh BP, Laffey JG. Hypocapnia and the injured brain: more harm than benefit. Crit Care Med. 2010;38:1348-59.

20. Pappalardo F, Pieri M, Greco T, Patroniti N, Pesenti A, Arcadipane A, et al. Predicting mortality risk in patients undergoing venovenous ECMO for ARDS due to influenza A (H1N1) pneumonia: the ECMOnet score. Intensive Care Med. 2013;39:275-81. 